21.2

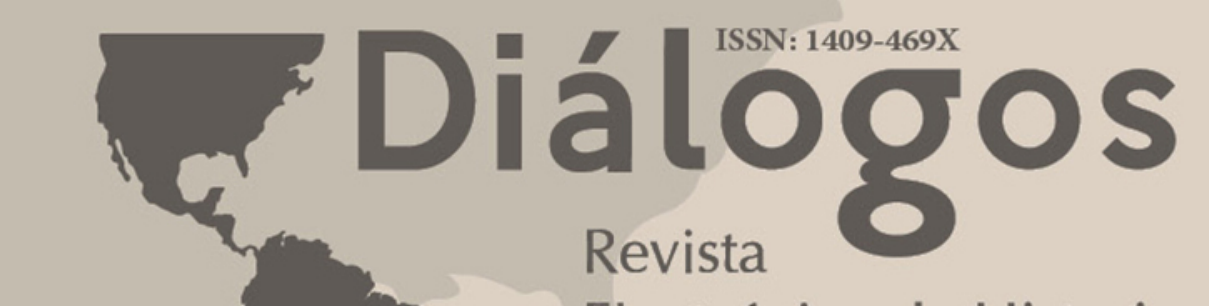

Electrónica de Historia

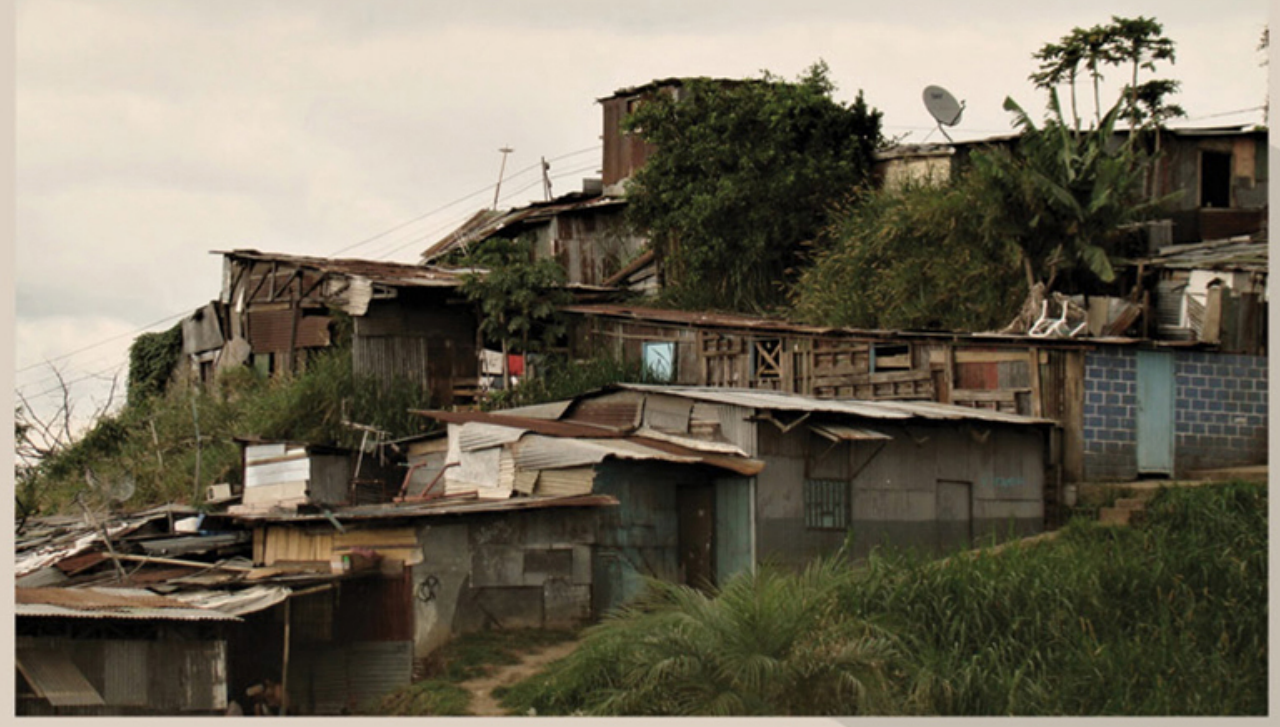

Centro de Investigaciones Históricas de América Central. Universidad de Costa Rica Julio-diciembre 2020

url: http://revistas.ucr.ac.cr/index.php/dialogos/index
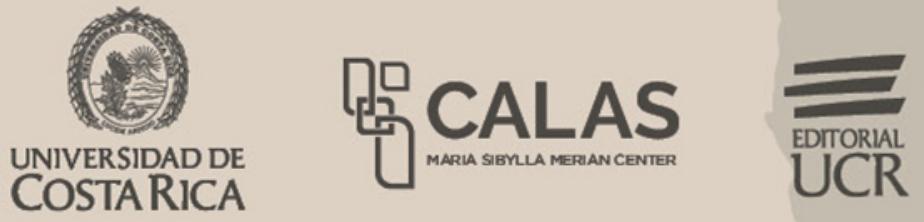


\title{
AGUA EN DISPUTA: CONTIENDA POLÍTICA Y GESTIÓN INSTITUCIONAL EN EL CASO DEL PARQUE LOS CHORROS, TACARES (2011-2019)
}

\author{
María Stephanie Valenciano Hernández \\ Karol Rojas Quesada
}

\begin{abstract}
Resumen
El presente artículo consiste en un análisis del conflicto socioambiental acaecido entre los años 2011 y 2018 que enfrentó a dos comunidades vecinas, pero principalmente a una comunidad y al Estado por las fuentes de agua del parque Los Chorros. Este análisis se realiza a partir del modelo de la Espiral del Poder y el Ciclo de las Demandas Políticas propuesto por Alpízar (2013), con las cuales se busca comprender cuáles fueron las percepciones de la causa del conflicto, las demandas y las estrategias de articulación de los actores políticos de la comunidad, y posteriormente, el procesamiento institucional que le dio el Estado costarricense a estas. Para esto se utiliza un diseño de investigación cualitativo que busca identificar principalmente los marcos cognitivos con los cuales los actores explican lo sucedido. Así es posible determinar las desigualdades existentes entre las comunidades y las prácticas paternalistas e impositivas con las que el Estado gestiona el agua, así como entre los mismos actores de las comunidades.
\end{abstract}

Palabras clave: conflicto socioambiental, gestión del agua, demandas políticas, conflictividad hídrica, Tacares, Costa Rica. 


\title{
WATER DISPUTE: POLITICAL CONTEST AND INSTITUTIONAL MANAGEMENT IN THE CASE OF LOS CHORROS PARK, TACARES (2011-2018)
}

\begin{abstract}
This article consists in an analysis of the socio-environmental conflict that confronted two neighboring communities, but mainly one community and the State due to the water sources of Parque Los Chorros, between 2011 and 2018. This analysis is based on the model of the Spiral of Power and the Cycle of Political Demands proposed by Alpízar (2013), which seeks to understand what were the perceptions of the cause of the conflict, the demands and the articulation strategies of the political actors of the community, and later, the institutional processing that the Costa Rican State gave them. For this, is applied a qualitative research design that mainly identifies the cognitive frameworks with which the actors explain the conflict. Thus, it is possible to determine the existing inequalities between the communities and the State with the paternalistic practices with which manages water, as well as between the same community actors.
\end{abstract}

Keywords: socio-environmental conflict, water management, political demands, water conflict, Tacares, Costa Rica. 


\section{INTRODUCCIÓN}

Los escenarios de conflictividad socioambiental por el agua han estado históricamente presentes en América Latina, de ahí que se hayan desarrollado amplios esfuerzos de investigación sobre estos, muchos de los cuales han sido englobados en redes como WATERLAT-GOBACIT. De estas es posible señalar dos vertientes: por un lado, aquellas investigaciones que estudian la temática con un enfoque en los Derechos Humanos y, más específicamente, el derecho humano al agua potable y las prácticas de gestión de este recurso (Foronda, 2008; Caba1lero, 2008; Ávila, 2008; Viñuales, 2008; Vallejo, 2011; Mar, 2012; Pare, 2012; Collado, 2012; Galindo, 2012; Hidalgo, 2012; Sánchez-García, 2015; Echeverría, 2017; Mora, 2017); y por otro lado, aquellas que se centran en estudiarlos a partir de criterios políticos como la desigualdad en el acceso al agua y la ecología política (García, 1999; Pérez, Santamaría \& Piña, 2006; Castro, 2008; Peña, 2008; Castro, 2012; Castro, Kloster \& Torregrosa, 2004; Bazán, 2012; Bottaro, Latta \& Sola, 2014; Latta \& Gómez, 2014; Bautista, 2016).

Esta presencia de conflictividad también ha sido una realidad de nuestro país. En Costa Rica, desde la década de los años 80 hasta el 2017, es posible contabilizar 441 contiendas políticas por agua que han llegado a ser abordadas por medios de comunicación escrita, de las cuales el tipo más recurrente es por el acceso a agua potable, seguido por la protección de cuerpos de agua y, por último, reclamos por un inadecuado saneamiento (Alpízar, 2019, p. 27). Si bien, de acuerdo con Alpízar (2019), no es posible hablar de un crecimiento sostenido de la ocurrencia de estas contiendas (pp. 25-27), es claro que se puede afirmar que han estado presentes a lo largo de los años en el escenario político nacional.

Estos conflictos, sin embargo, pueden ser cada vez más frecuentes frente a realidades que apuntan hacia una potencial escasez del agua a raíz de sequías ahora más recurrentes y prolongadas, articulando consigo luchas entre grupos con intereses contrapuestos en diferentes niveles (local, regional, nacional y mundial) por el su control y empleo (Segrelles, 2007). Sobre las cuales tienen un papel muy relevante la movilización de los recursos hídricos de un lugar a otro para sus distintos usos en lugares distintos (Swygendouw, 2019, pp. 48-49).

Este es precisamente el caso del conflicto socioambiental por las fuentes de agua del parque Los Chorros, donde en el 2011 el Instituto Costarricense de Acueductos y Alcantarillados (AyA) buscó desarrollar el proyecto de Mejoras al Sistema de Abastecimiento de Atenas, con el cual buscaba tomar agua del acueducto ubicado en esta área para solucionar las demandas por abastecimiento del cantón vecino, tras haber sido declarado en emergencia sanitaria por la escasez que enfrentaba. Sin embargo, lo que parecía ser una no muy complicada inversión en mejorar la infraestructura terminó por articular un conflicto que se extendió por cerca de ocho años y enfrentó a dos comunidades vecinas entre sí ${ }^{1}$ y con el Estado. 
El objetivo de este artículo es analizar este conflicto socioambiental en tres etapas principalmente abordadas en el modelo de la Espiral del Poder y el Ciclo de las Demandas Políticas planteado por Alpízar (2013): construcción de las demandas políticas, articulación de las demandas políticas y procesamiento institucional de las demandas políticas. A partir de estas, se busca comprender para el caso cuál y cómo fue la interacción entre la comunidad de Tacares y el Estado costarricense durante el período de conflictividad a través de la identificación de demandas, estrategias de articulación de las demandas y respuestas institucionales que se dieron a éstas.

Para esto, en primer lugar, se contextualiza el conflicto en estudio con el propósito de abordar brevemente qué ha sucedido desde su inicio y quiénes son las comunidades implicadas. En segundo lugar, se presenta un abordaje teórico que permita comprender y estudiar a profundidad el caso. En tercer lugar, se explica el diseño metodológico con el cual se desarrolló este estudio y se crearon los respectivos marcos estudiados posteriormente. Luego, se detallan los marcos encontrados sobre la causa del conflicto y las demandas de la comunidad de Tacares, para luego determinar las respuestas institucionales dadas a éstas. Finalmente, se presentan algunas de las reflexiones finales que son posibles desarrollar a partir de los resultados.

\section{CONTEXTUALIZACIÓN}

Atenas es el quinto cantón de la provincia de Alajuela. Se compone de ocho distritos, tiene una población total de 25460 habitantes y el abastecimiento del servicio hídrico es brindado por el AyA. Este cantón ha venido atravesando importantes dificultades para tener un acceso permanente al agua en sus comunidades, dado que "el servicio de agua potable solo funciona entre las 3 a. m. y las 6 a. m." (Barrantes, 2014). Esto a su vez ha conllevado al cierre de centros educativos y comedores escolares ante la incapacidad de los mismo de satisfacer esta necesidad básica de los estudiantes. De acuerdo con datos brindados por la Municipalidad de Atenas al medio escrito La Nación en el 2014, un 60 \% de sus habitantes sufría de racionamientos diarios de agua (Fornaguera, 2014, párr. 2). Esta escasez de agua llevó incluso a la declaración de una emergencia sanitaria emitida por Laura Chinchilla Miranda, la entonces presidenta de la República a través de La Gaceta con el decreto_No $38005-\mathrm{S}$. También generó que se interpusiera un recurso de amparo ante la Sala Constitucional en el año 2011, que fue dado con lugar, por lo que se le ordenó al subgerente general del AyA girar de inmediato las órdenes que estaban dentro del ámbito de sus competencias (Sala Constitucional de Costa Rica, 2011, 07-008098-0007-CO).

Para abordar la emergencia y ante la falta de nacientes para cubrir a toda la comunidad de Atenas, el Instituto Costarricense de Acueductos y Alcantarillados (AyA) inició en diciembre del 2012 el proyecto Mejoras al Sistema de Abastecimiento de Atenas. Su objetivo consistía en aumentar el caudal de agua de la captación 
del Parque Los Chorros en Grecia (Ver Figura 1), para trasladarlo a Atenas y así solucionar el problema que enfrenta dicha comunidad. Este proyecto tenía un costo de 2.800 millones de colones, financiados por el empréstito BCIE-AYA 1725.

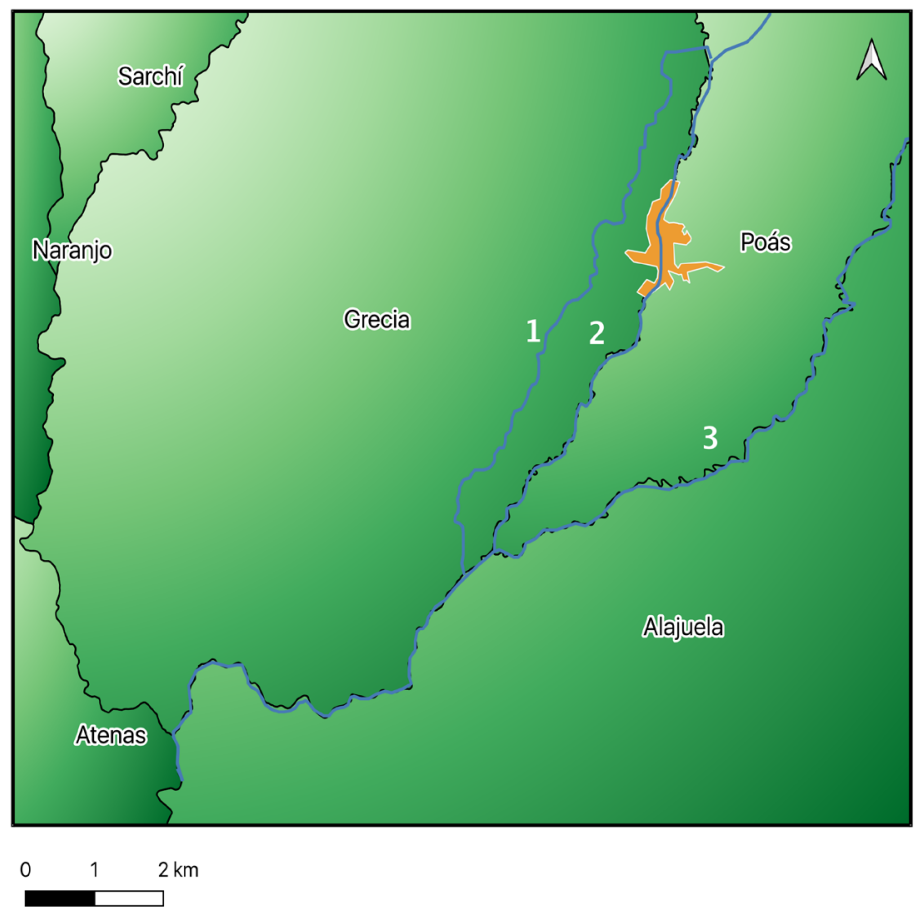

\section{Localización del Parque Recreativo Municipal Los Chorros según la división territorial cantonal}

Simbología

- Río Tacares (1)

— Río Prendas (2)

— Río Poás (3)

- Parque Rec. Municipal Los Chorros

Sistema de Proyección: CRTM05

Datum: WGS84

Fuente: SNIT, 2019

Elaborado por: MaríaS

Valenciano $\mathrm{H}$.

Año 2019

Figura 1. Mapa: Localización del Parque Recreativo Municipal Los Chorros. Fuente: Elaboración propia.

La ejecución del proyecto conllevaba dos etapas. La primera contemplaba 23 kilómetros de tubería y un tanque de almacenamiento de 2500 metros cúbicos en Sabana Larga para distribuir agua a la comunidad de Atenas. La segunda etapa planeaba ser paralela y proyectaba adherirse a la captación actual de Tacares. Sin embargo, los datos que el AyA provee en la redacción de su proyecto denotaban planes muy distintos.

Tacares, por su parte, es el quinto distrito del cantón de Grecia ubicado en la provincia de Alajuela. Este posee una población de poco más de 8000 habitantes y la administración y manejo del recurso hídrico está en manos de la ASADA². Un mes después de haber iniciado la ejecución de este proyecto, es decir, en enero del 2013, la comunidad de Tacares se enfrentó con el AyA a raíz de las dudas que este les generaba. Argumentaban la falta de información dada por la institución y la ausencia de una consulta popular a los vecinos de dicha comunidad, lo cual era pertinente en tanto el proyecto se estaba desarrollando a partir de la fuente de agua que les abastecía. Con el objetivo de continuar las negociaciones, la comunidad de Grecia acordó a finales de enero del 2013 formar una comisión técnica legal que se reuniría en las oficinas centrales del AyA con altos funcionarios de dicha institución para buscar una solución conjunta (Bolaños, 2013,p. 8). 
Durante todo este lapso de tiempo, es decir entre 2011 y 2018, el conflicto se mantuvo vigente con períodos que variación entre mayor y menor conflictividad. Asimismo, se caracterizó por la entrada y salida de actores tanto no institucionales como institucionales, unos por desacuerdos a lo interno de la comunidad y otros por cambios en el escenario político a nivel nacional. Asimismo, con estrategias y discursos sumamente variantes entre sí, que conllevaron al aplazamiento de ejecución del proyecto y condición por casi una década más el acceso a agua potable en el cantón de Atenas.

\section{ABORDAJE TEÓRICO}

La conflictividad está siempre presente en el estudio de lo político. Para Mouffe (2007), los asuntos propiamente políticos siempre implican decisiones que requieren que optemos entre alternativas en conflicto. Lo político precisa, por lo tanto, de dinámicas con una naturaleza antagonista que distan de las propuestas liberales que conciben la capacidad de generar escenarios armoniosos y no conflictivos frente a realidades pluralistas de valores y perspectivas. Este antagonismo, por ende, articula una distinción nosotros/ellos que es condición de la posibilidad de formación de identidades políticas cuando el "ellos" cuestiona la identidad del "nosotros" y se considera una amenaza a su existencia. Por lo tanto, se parte de que todo orden es político y está basado en alguna forma de exclusión, pues siempre existen otras posibilidades que han sido reprimidas y pueden reactivarse (Mouffe, 2007, pp. 23-25).

Así, reconocer el carácter perenne de la conflictividad en lo político no es incompatible con la democracia misma porque el carácter democrático de una sociedad solo puede venir dado por el hecho de que ningún actor social limitado pueda atribuirse la representación de la totalidad y afirmar que tiene el control de los fundamentos. De esta forma, la práctica política no se concibe como algo que simplemente representa los intereses de unas identidades previamente constituidas, sino que debe entenderse como algo que constituye las propias identidades en un terreno considerado precario y vulnerable (Mouffe, 2000, p. 113). Lo cual puede conllevar a que se generen roces en el sistema de representatividad democrática.

Para Pitkin (1985), la representación ${ }^{3}$ política es ante todo un concierto público e institucionalizado que involucra a muchas personas y grupos, que opera de acuerdo con los complejos modos en los que lo hacen los conciertos sociales a gran escala. Lo que lo constituye como representación no es cualquier acción singular realizada por cualquier participante, sino la estructura global, el funcionamiento del sistema y las pautas que son producto de las múltiples actividades de mucha gente, de modo que es representación si el pueblo está presente en la acción gubernamental. En la medida en que se trata de una cuestión de actuar sustantivamente por otros, esto requiere una acción independiente en interés de los gobernados (p. 247). 
De modo que, la representación significa actuar en interés de los representados de una manera sensible ante ellos (Pitkin, 1985. p. 233). Sin embargo, la autora es clara en plantear el problema que puede presentarse al contraponer los intereses locales o parciales versus el interés nacional y la cuestión del papel del representante político con respecto a ellos. Frente a estos escenarios, los actores buscan organizarse en la consecución de sus intereses, articulando así acciones individuales o colectivas que suelen ser identificadas como participación política no convencional debido a su proximidad (o no) a la normatividad (Contreras, Correa \& García, 2005, p. 187). Por ende, se entiende esto al uso o no de canales brindados por la propia institucionalidad para incidir sobre la esfera política y la toma de decisiones a partir de la organización y la constitución de actores colectivos.

Un actor ${ }^{4}$ colectivo es definido de acuerdo con Dente y Subirats (2014) como un conjunto de sujetos cuyos mecanismos de interacción entre sí tienen una estabilidad y una fuerza suficiente como para asegurar que quienes hablen en su nombre representen efectivamente los intereses y los objetivos de la unidad superior como tal y no exclusivamente los suyos (p. 76). Cuando los actores colectivos consideran que sus intereses y valores no son representados por quienes ostentan los cargos de representación política y que en la esfera institucional no solo estos no se ven reflejados, sino que incluso se genera política pública que consideran amenaza sus entornos más directos, pueden buscar ejercer una participación política que precisamente tiende a desplazar los medios y canales más tradicionales dados desde una esfera institucional. Lo que genera dichas acciones colectivas y que, a su vez, pueden nutrirse de una participación política considerada no convencional.

Los escenarios recientes respecto a la gestión y acceso al recurso hídrico configuran retos cada vez más complejos que a su vez desencadenan luchas y conflictos entre grupos con intereses contrapuestos (Segrelles, 2007, pp. 7-8). Esto a su vez, frente a una inflexión extractivista, ha conllevado a la explosión de conflictos socioambientales ${ }^{5}$ que tienen por protagonistas a organizaciones indígenas y campesinas, así como de nuevas formas de movilización y participación ciudadana centradas en la defensa de los bienes naturales, la biodiversidad y el ambiente (Svampa, 2013, p. 39).

Para analizar este conflicto, se recurre al modelo de Alpízar (2013) de la Espiral del Poder y el Ciclo de las Demandas Políticas, que presenta cuatro fases específicas y de las cuales se estará utilizando tres en este caso. La primera consiste en la construcción o destrucción de las demandas de los actores políticos según la cual se busca estudiar la forma en que los intereses y/o preferencias se convierten en demandas políticas. La segunda se trata de la articulación o desarticulación de las demandas según la cual una vez que los actores políticos colocan sus demandas en un espacio público ya no solo depende de los actores en sí mismos, sino de las complejas interrelaciones que ocurren entre los distintos actores, medios de comunicación, partidos políticos y las instituciones públicas. 
La tercera fase es el procesamiento institucional de las demandas que se trata de todas aquellas acciones u omisiones de las autoridades gubernamentales en relación con las demandas planteadas por los actores (Alpízar, 2013.pp. 37-41).

\section{DISEÑO METODOLÓGICO}

Se trata de un diseño de investigación cualitativo que reconstruye el conflicto a través de tres etapas: construcción/destrucción de demandas políticas, articulación/ desarticulación de demandas políticas y procesamiento institucional de demandas políticas. Para este se utilizan, como técnicas de recolección de información, la aplicación de entrevistas semiestructuradas a actores de la comunidad de Tacares y actores institucionales, la revisión bibliográfica de actas institucionales y medios de comunicación local y nacional. A estas fuentes se les desarrolló un análisis de contenido y para algunas más específicamente se utilizó el análisis de marcos cognitivos $^{6}$ para identificar los frames de los actores sobre las causas del conflicto y las demandas construidas. Asimismo, se identificaron mediante las entrevistas realizadas las estrategias de articulación desarrolladas por los vecinos de Tacares y las respuestas institucionales que dio el Estado a sus demandas.

Para el caso del análisis de marcos, la información recolectada fue organizada por tipos de actores y procesada a través del programa informático Atlas. ti en unidades hermenéuticas separadas, con las cuales se generaron una serie de códigos para el procesamiento de entrevistas, notas periodísticas y documentación institucional. A partir de estos códigos, que se muestran en la Tabla 1, fue posible más tarde seleccionar frases de las declaraciones encontradas con las cuales se identificaron los marcos empleados por los diferentes actores para referirse al conflicto y a todo lo que este implicó. Estas categorías empleadas para el análisis fueron basadas en la teoría y los conceptos pertinentes a la investigación. De esta forma, como sostienen Alonso, Volkens y Gómez (2012), se busca contener suficientes códigos para recoger todos los detalles importantes (p. 24). 
TABLA 1

Códigos utilizados en el procesamiento y análisis de información

\begin{tabular}{|c|c|c|c|}
\hline IDENTIFICADOR & TIPO DE ACTOR & CÓDIGO & REFERENCIA \\
\hline 105 & $\begin{array}{l}\text { Actores institucionales } \\
\text { locales y nacionales }\end{array}$ & $\begin{array}{l}\text { Percepción institucional } \\
\text { de las causas del conflicto }\end{array}$ & $\begin{array}{l}\text { Referencias de los actores } \\
\text { institucionales sobre qué } \\
\text { consideran que originó el } \\
\text { conflicto en estudio. }\end{array}$ \\
\hline 106 & & $\begin{array}{c}\text { Respuestas institucionales } \\
\text { al conflicto }\end{array}$ & $\begin{array}{l}\text { Referencias de los actores } \\
\text { institucionales sobre de las } \\
\text { demandas articuladas por los } \\
\text { actores de la comunidad. }\end{array}$ \\
\hline 203 & Actores comunales & $\begin{array}{l}\text { Percepción comunal de } \\
\text { la causa del conflicto }\end{array}$ & $\begin{array}{l}\text { Referencias de los actores } \\
\text { comunales sobre qué } \\
\text { consideran que originó } \\
\text { el conflicto en estudio. }\end{array}$ \\
\hline 204 & & Organización y estrategias & $\begin{array}{l}\text { Referencias de los actores } \\
\text { comunales sobre la forma } \\
\text { en que se organizaron y las } \\
\text { estrategias que emplearon para } \\
\text { articular sus demandas en } \\
\text { el Estado. }\end{array}$ \\
\hline 205 & & Demandas comunales & $\begin{array}{c}\text { Referencias de los actores } \\
\text { comunales sobre cuáles eran } \\
\text { las demandas y peticiones que } \\
\text { llevaron a las instituciones } \\
\text { del Estado. }\end{array}$ \\
\hline 206 & & $\begin{array}{l}\text { Causas de la fractura } \\
\text { del bloque comunal }\end{array}$ & $\begin{array}{l}\text { Referencias de los actores } \\
\text { comunales sobre las razones } \\
\text { por las cuales la comunidad se } \\
\text { dividió durante el conflicto. }\end{array}$ \\
\hline
\end{tabular}

\section{LOS MARCOS COGNITIVOS SOBRE LA CAUSA DEL CONFLICTO}

La ejecución de este proyecto dio inicio en diciembre del año 2012 y encontró sus primeros obstáculos un mes después cuando en enero del año 2013 los vecinos de Tacares hicieron pública su inconformidad con las obras que se estaban desarrollando en las inmediaciones del Parque Los Chorros, por lo que se enfrentaron a las autoridades del AyA en búsqueda de información sobre lo que se estaba desarrollando en el lugar y las implicaciones que esto podría tener a futuro. 
A la posición de la comunidad se sumó además el gobierno local de Grecia, quienes en el momento se mostraron a favor de las posiciones mostradas por la comunidad de Tacares. Estas posiciones sin embargo no eran suscritas ni comprendidas por los actores institucionales nacionales representados por el AyA.

En la Figura 2 es posible observar los distintos marcos identificados sobre las causas del conflicto, señaladas por los diferentes actores vinculados al mismo. De esta manera, se ve que los actores institucionales nacionales plantean un frame que es constantemente identificado, se trata de acaparamiento del recurso más específicamente por parte de los miembros de la comunidad de Tacares y de Grecia en general que, de acuerdo con ellos, desafió una gestión institucional que buscaba la distribución equitativa de los recursos. Este marco también es empleado por la Municipalidad de Atenas en actas institucionales, pues aducen la causa no solo en un acaparamiento del recurso, sino también en la búsqueda de intereses particulares así como a la desinformación existente entre los vecinos de Tacares.

Por otro lado, se encuentra la Municipalidad de Grecia, que en respaldo del movimiento de los vecinos de Tacares, enmarca la causa del conflicto en el debido proceso, señalando que el AyA no tramitó los permisos que le correspondían ni comunicó de la manera adecuada a la comunidad sobre el proyecto. Finalmente, los vecinos de Tacares emplean seis distintos marcos identificables en las entrevistas con estos actores y declaraciones a medios de comunicación que, de acuerdo con sus versiones, explican el detonante del conflicto en este caso. La más señalada en todo momento es la escasa información brindada por parte del AyA, cuestión que suscitó una gran desconfianza por parte de los vecinos al no tener seguridad sobre la afectación que este proyecto podría generar sobre sus cotidianidades.

A partir de la identificación de todos estos marcos es constatable como las estrategias de los actores en cada caso pasan por la no asunción de la responsabilidad sobre las causas del conflicto. Por un lado, los actores institucionales, a grandes rasgos, culpabilizan a la comunidad de desatar una disputa por el recurso bajo el argumento de un Estado que buscaba la equitativa distribución de los recursos y, por el otro, los actores locales para quienes lo sucedido pasaba por la responsabilidad de un Estado con políticas impositivas y la negativa a comunicar e informar según el debido proceso.

Estos marcos utilizados por los miembros de la comunidad pueden vincularse con un concepto con gran potencial explicativo para el caso, como lo es el despojo, en tanto que estos actores apelan a una falta de autonomía territorial respecto a la toma de decisiones sobre recursos y espacios sobre los cuales se tienen vínculos estrechos. Ojeda (2016) define el despojo como un proceso violento de reconfiguración socioespacial y, en particular, socioambiental, que limita la capacidad que tienen las comunidades de decidir sobre sus medios de sustento y sus formas de vida (p. 21). 


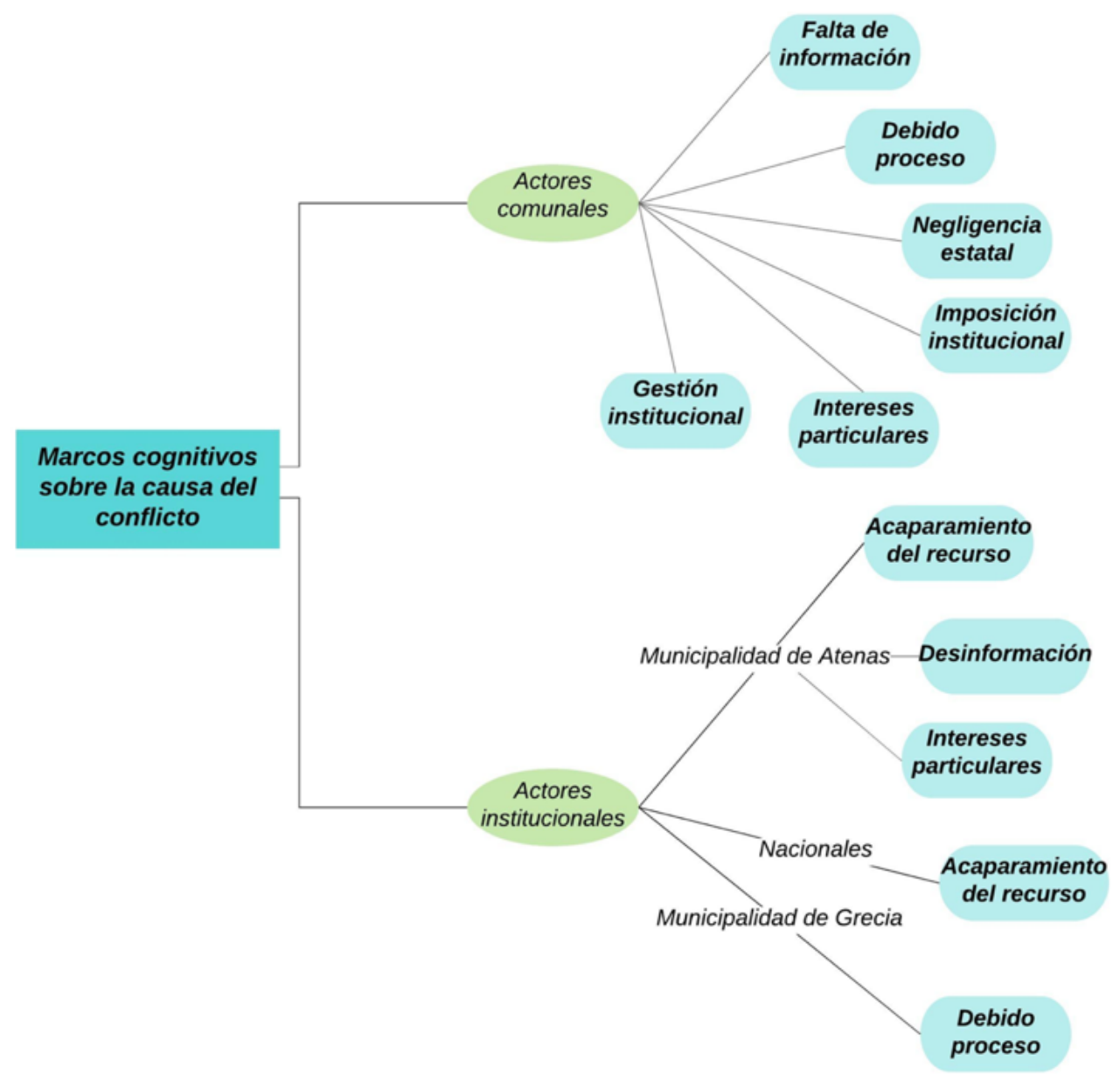

Figura 2. Marcos sobre la causa del conflicto. Fuente: Elaboración propia.

\section{MARCOS COGNITIVOS SOBRE DEMANDAS POLÍTICAS CONSTRUIDAS Y ESTRATEGIAS DE ARTICULACIÓN}

Este proceso es definido por Alpízar (2013) como el momento en el cual un grupo de actores recoge una serie de constelaciones de problemas y los llevan al espacio público para su problematización, dando origen al proceso de construcción y destrucción de las demandas políticas. Así, ciertos intereses compartidos por un grupo se transforman en una serie de reivindicaciones políticas que son seleccionadas como asuntos de relevancia mediante la también revisión de las oportunidades políticas. Para sacar provecho de estas ventanas de oportunidad política, como menciona Alpízar (2013), se deben de tener en cuenta los marcos cognitivos de los actores políticos, que es donde los asuntos del mundo de la vida son elaborados intersubjetivamente en discursos ideológicos específicos (pp. 34-35). 
Los marcos a través de los cuales la comunidad llevó a cabo la construcción de sus demandas pueden dividirse en tres grupos distintos como se muestra en la Figura 8: marcos procedimentales y garantistas que apelan a las formas en cómo debía llevarse a cabo el proceso de construcción del proyecto y los derechos de la comunidad frente a este, marcos conservacionistas que se enfocan en la protección de la naturaleza del Parque Los Chorros, y finalmente, los marcos de replanteamiento que buscan establecer alternativas a lo planteado por el fondo en el proyecto de Mejoras al Sistema de Abastecimiento de Atenas.

Para cada uno de los grupos es posible identificar distintos marcos utilizados. El primer grupo de marcos, es decir, los que corresponden a demandas por cuestiones procedimentales y garantistas, apelan al Estado utilizando cuatro marcos distintos. En primer lugar, señalan la información como una demanda, o bien, el acceso a más información sobre el proyecto que se llevaría a cabo previo a su propia ejecución, así como las implicaciones del mismo para la comunidad. Para este encuadre es posible identificar expresiones como "era información lo que queríamos que nos dieran" (Comunicación personal con informante clave 3, 22 de mayo del 2019).

En segundo lugar, se identifica el marco de la "participación" a través del cual los vecinos reclaman a las instituciones no ser tomados en cuenta en el planteamiento y diseño del proyecto. Este punto es además respaldado por SETENA (2014) cuando indica que se deben desarrollar procesos participativos con la comunidad en la etapa de construcción del proyecto que garantice la debida información de las comunidades (p. 8). Respecto a este frame, se encuentran declaraciones como "fue decirle al AYA ustedes no son la verdad absoluta en esto y tienen que tomarnos en cuenta" (Comunicación personal con informante clave 1, 10 de abril del 2019), donde los vecinos establecen un descontento por la forma impositiva y vertical de hacer y desarrollar política pública.

Aunado a esto, la comunidad de Tacares hace uso del marco del "debido proceso" a través del cual le solicita a las instituciones que se llevara a cabo el proyecto apegándose a lo determinado por la normativa legal, sobre todo en lo que respecta a permisos de ejecución del mismo. Así, para este encuadre, se identifican expresiones como la siguiente, donde un miembro de la comunidad explica que, en su demanda por procedimientos apegados a las normas, recurren a la Sala Constitucional: "la anomalía en la forma en que se tramitó el permiso ante SETENA envió el recurso a la sala IV y se dio lo que nosotros sabíamos que iba a pasar que se votó a favor nuestro y suspendieron las obras" (Comunicación personal con informante clave 4, 30 de julio del 2019).

Finalmente, el cuarto marco utilizado se trata de "derecho a protesta" a través del cual algunas personas buscaban rescatar la garantía de la comunidad de manifestar su descontento con respecto a las estrategias que la institucionalidad estaba llevando a cabo para la ejecución del proyecto y las respuestas que en un inicio estaba brindando a los vecinos de Tacares al plantear estos sus inquietudes. Para lo anterior, se articulaban expresiones como "el derecho a protestas es un derecho que tienen todos los costarricenses" (Comunicación personal con informante clave 4, 30 de julio del 2019). 
A través de esto algunos miembros de la comunidad dejan claro que este sería uno de sus repertorios de acción como producto del descontento. Además, por medio de este marco los vecinos exponen la existencia de uno de los cuatro principios claves de los regímenes representativos expuesto por Manin (2006), según el cual debe de existir la libertad de expresión de quienes son gobernados (p. 7).

El segundo grupo de marcos, los conservacionistas, articulan las demandas en cuatro encuadres distintos. En primer lugar, se identifica el de "protección del ecosistema" a través del cual los vecinos de la comunidad demandan que el proyecto en cuestión no tenga impactos sobre la naturaleza que existe en el Parque Los Chorros y que se asegure que no habría implicaciones negativas para el espacio natural del mismo. Para este encuadre se encuentran citas de demandas como "que no se afectara el Parque Los Chorros", o algunas orientadas a cuestiones específicas del proyecto que podrían incidir de forma negativa sobre la naturaleza del lugar como la siguiente expresión: "había que hacer más estudios sobre la contaminación sónica, el impacto visual y todo eso que causa en los animales pero para mí y para todos eso era nefasto en ese momento" (Comunicación personal con informante clave 1, 10 de abril del 2019).

En segundo lugar, se encuentra el marco de "abastecimiento futuro" a partir del que la comunidad planteaba que debía asegurárseles una cantidad de agua a futuro capaz de abastecer una demanda creciente del recurso, dada por el aumento de población y de posibles desarrollos que podrían llevarse a cabo en el lugar. Al respecto, sin embargo, se identifican dos demandas distintas; por un lado, aquellas que solicitan no tomar el agua de dicha fuente por sus implicaciones futuras y, por otro, las que se encuentra de acuerdo de tomar el agua de la fuente siempre y cuando no haya afectaciones para su consumo. Para este se identifican expresiones como "déjenos esa agua para el crecimiento natural nuestro" (Comunicación personal con informante clave 3, 22 de mayo del 2019), "Tacares va a tener un desarrollo muy grande, de hecho ya es un acueducto enorme, y entonces déjenos esa agua para nosotros" (Comunicación personal con informante clave 3, 22 de mayo del 2019) o bien quienes solo decían necesitar "que no se afectara el caudal para la comunidad de Tacares" (Comunicación personal con informante clave 1, 10 de abril del 2019).

El último frame conservacionista que se identifica es el de "retribución", en el cual la comunidad solicitaba que por el uso del agua de Tacares se cobrara un canon hídrico a Atenas que permitiera invertir en la protección del parque y en la compra de los terrenos aledaños para la conservación de las fuentes de agua así como para involucrar y concientizar a la comunidad de Atenas sobre la importancia de esta área. Sobre este marco se encuentran citas como "entonces hay un tema que se llama canon hídrico, que ese canon hídrico se le debería cobrar a Atenas, pero no se le estaba cobrando" (Comunicación personal con informante clave 4, 30 de julio del 2019) o también "[Atenas] tienen que ser conscientes de donde viene esa agua, porque en los conflictos que había tenido los Chorros anteriormente que estuvo en peligro la captación del líquido aunque se invitaba a la gente de Atenas, nunca se unieron a luchar entonces siempre se manejó el discurso de concientizar" (Comunicación personal con informante clave 2, 19 de mayo del 2019). 
El tercer grupo de marcos, identificados como encuadres "de replanteamiento", buscan establecer cambios a la forma en que estaba solucionando el Estado la demanda de abastecimiento de agua de Atenas, es decir, buscaban su reforma: unos rediseñando el proyecto para tomar el agua del Parque Los Chorros y otros solicitando la búsqueda de otras fuentes. Para este grupo, el primer frame articulado es el de "rediseño del proyecto" con el cual los vecinos de Tacares solicitaban cambios sobre la forma en que estaba planteado en su etapa el parque para evitar los impactos que podría tener. Al respecto la demanda más i mportante era la de no construir una estación de bombeo y para la cual establecían alternativas como "que (se) llevara el agua por gravedad" (Comunicación personal con informante clave 3, 22 de mayo del 2019).

El segundo encuadre observado es el de "búsqueda de otras fuentes" con el cual algunos miembros de la comunidad apelaban a no tomar el agua de las nacientes del Parque Los Chorros y buscar otras fuentes alternativas a esta para abastecer la demanda de agua de los atenienses. Para este grupo de vecinos no había espacio para la negociación de las nacientes tacareñas y el AyA debía no insistir más sobre la toma del agua del parque en cuestión. Sobre este mismo argumento se planteaba como alternativa el uso de fuentes más cercanas a Atenas y se proponía que "solamente en Roca Verde, una urbanización ubicada en un cerro en Atenas, contaba con cerca de 40 piscinas, la propuesta era que se reuniera toda esa agua de pozos y se utilizara para la comunidad" (Comunicación personal con informante clave 1, 10 de abril del 2019).

A este marco se enlaza el de "exclusividad del recurso" a partir del cual algunos vecinos de Tacares demandaban que el agua de Los Chorros debía ser de uso estricto para su distrito y negaban la entrada del AyA al parque para el desarrollo del proyecto. De esta forma defendían una apropiación del recurso que de acuerdo con ellos debía ser respetada por el Estado y para la cual exigían que se retirara la maquinaria instalada en el lugar para la construcción del proyecto. Sobre este frame es posible identificar declaraciones como que "no permitirán que AyA ingrese al parque Los Chorros", e incluso "ustedes meten aquí aunque sea una cuchara y los matamos; les quemamos la maquinaria" (Murillo, 2014).

Mientras que, por otro lado, otro grupo de vecinos en un inicio hacía uso del encuadre de "uso de naciente alterna", con la cual le solicitaban al AyA que no tomara el agua de la fuente uno que abastecía Tacares y Poás, sino que hiciera uso de la fuente dos que se encuentra anexa a la uno y que hasta el momento se encuentra sin explotar. Así se identifican declaraciones como "el primer comité no se oponía a que el AyA tomara el agua, pero era que lo tomara de otra parte, no de la captación actual" (Comunicación personal con informante clave 4, 30 de julio del 2019) o "[pedíamos] que el AyA construyera otra captación en otra naciente dentro del Parque Los Chorros 7 " (comunicación personal con informante clave 2, 19 de mayo del 2019). 


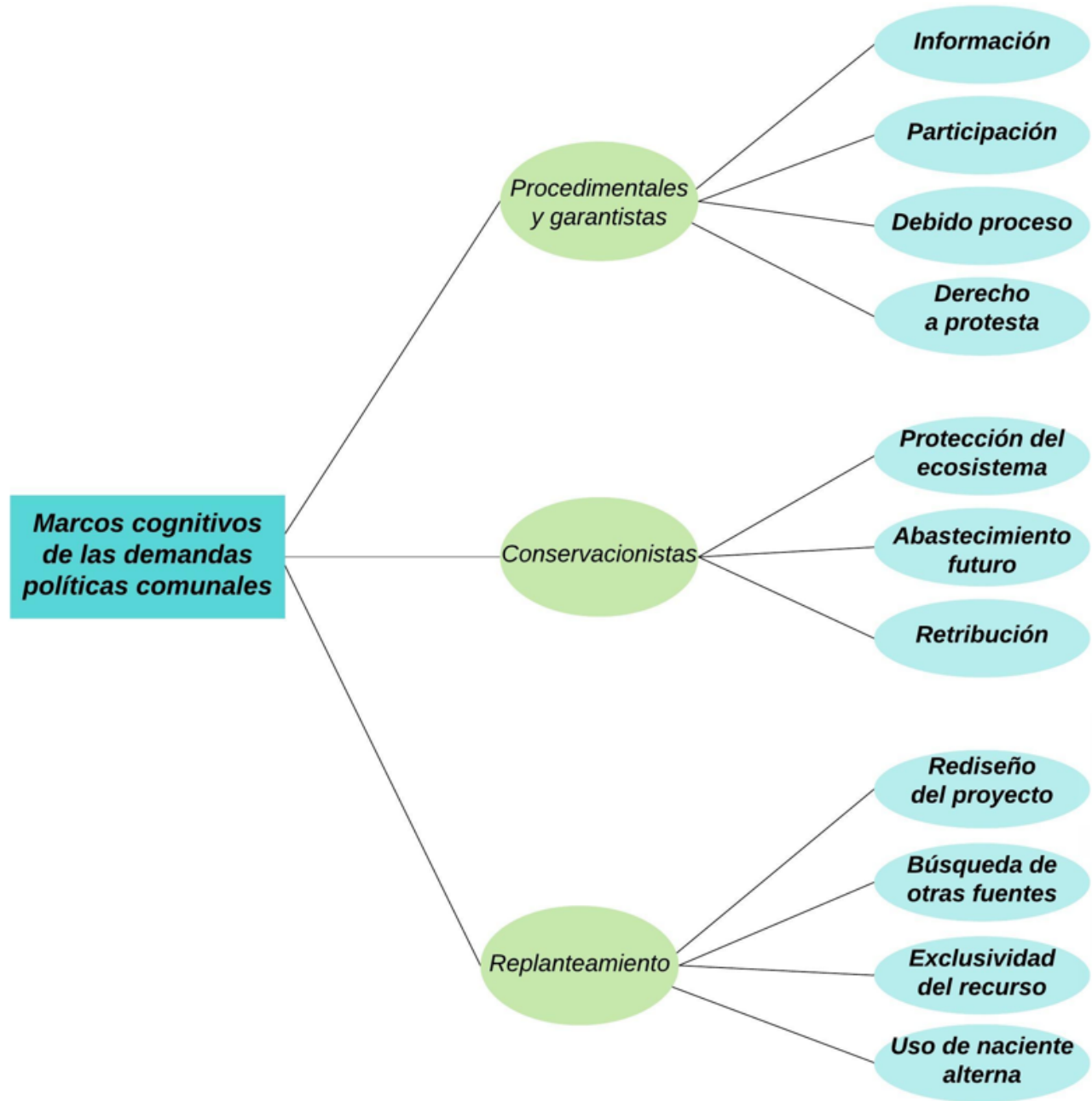

Figura 3. Marcos cognitivos sobre las demandas construidas por la comunidad. Fuente: Elaboración propia.

A través del conflicto es posible observar que si bien todos los vecinos de Tacares buscaban incidir sobre la manera en que el Estado gestiona el agua de las nacientes del Parque Los Chorros, mediante formas de control social, éstas no iban todas orientadas a una misma dirección. Con esto se apunta a que es claro que había una demanda por participación e información que era constante entre los actores de la comunidad, empero esta parecía dividirse entre un grupo dispuesto a compartir el recurso y otro cuyas intenciones estaban más pendientes de resguardar el agua para el uso exclusivo de Tacares como se verá más adelante. Es decir, dentro de la misma comunidad era posible encontrar evidencias de la naturaleza antagonista que atraviesa lo político. 
Así, se identifican entonces dos grupos de actores comprendidos de esta forma a partir de Dente y Subirats (2014) por sus acciones en búsqueda de incidir en la política pública. Así, como se plantea en la Figura 4, por un lado quienes en un inicio integran la Comisión Técnica Negociadora, y por otro, el grupo que prevalece después de la renuncia de este primer conjunto de actores. El primero caracterizado por una mayor apertura al diálogo y a la negociación con las instituciones, y el otro por estrategias más duras (como se verá en más adelante) y con menor disposición a ceder respecto a sus peticiones, para lo cual apelaban a encuadres como el de exclusividad del recurso o búsqueda de otras fuentes.

El primer grupo se caracterizaba por el liderazgo de cuatro vecinos, quienes conformaron un grupo de trabajo interdisciplinario entre especialistas en derecho, gestión ambiental y uso de tecnologías. Mientras que el segundo grupo giró en torno al liderazgo de un solo miembro de la comunidad. Por un lado, el primero apelaba a estrategias integrativas de negociación, es decir, un ganar-ganar, y el segundo a estrategias distributivas, pese a que es posible pensar que en negociaciones por conflictos por agua los estilos competitivos no generan soluciones viables y beneficiosas (Petrescu, Gavriletea y Petrescu, 2011, p. 17).

Es viable, por tanto, identificar un enfoque adversarial y no adversarial entre los dos grupos articulados por los vecinos durante el conflicto. Es decir, uno que leía la situación en términos de competencia por la obtención de sus intereses y otro que apuntaba, por el contrario, a la búsqueda de una solución que tomara en cuenta las necesidades e intereses de todas las partes (pp. 12-13), siendo para el caso el AyA, Atenas, las comunidades vecinas y por supuesto, Tacares. 


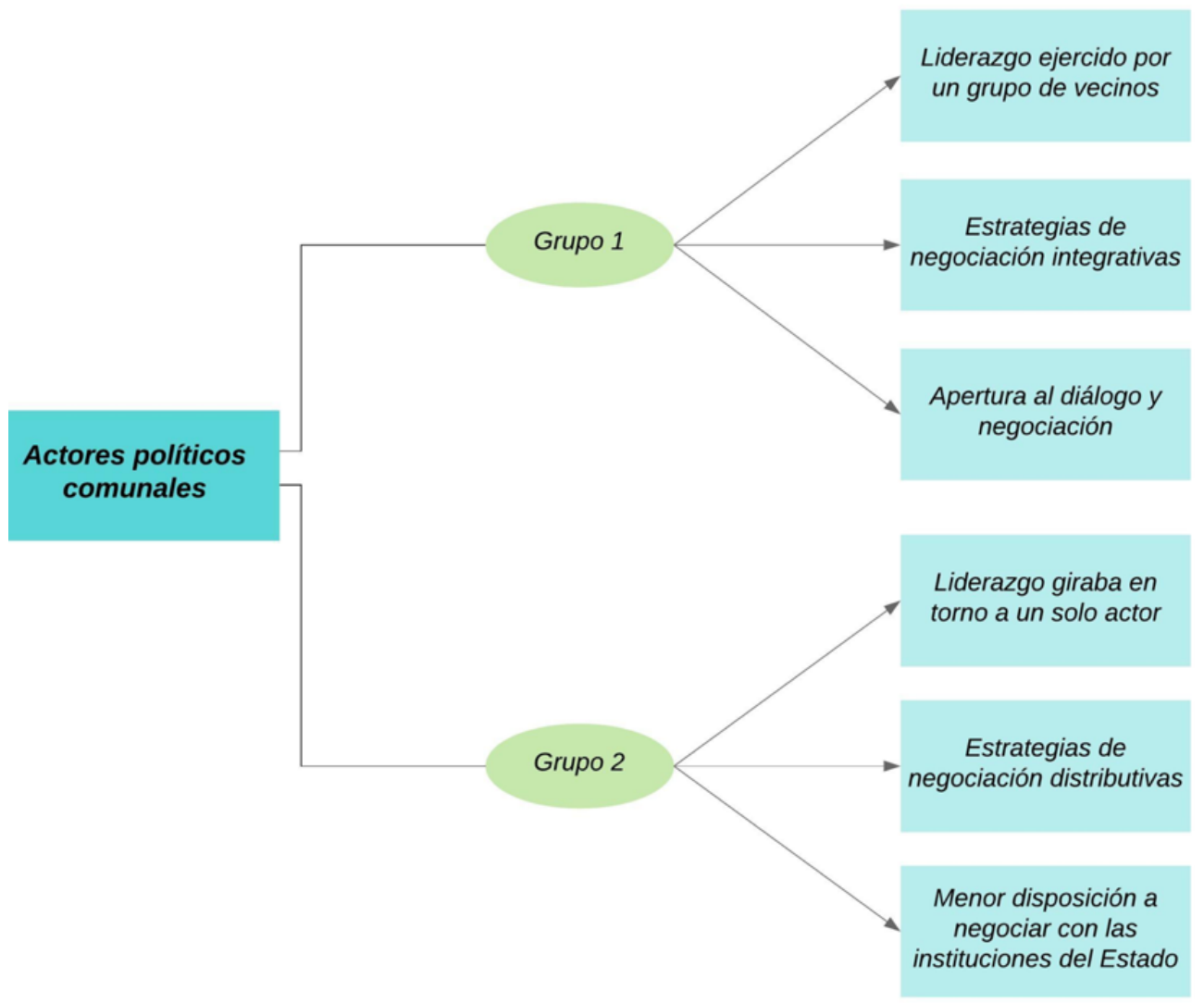

Figura 4. Bloques de actores políticos comunales. Fuente: Elaboración propia.

Una vez que todas estas demandas son construidas y puestas en el espacio público, estas deben ser articuladas. Esta articulación no solo depende de los actores en sí mismos, sino de las complejas interrelaciones que ocurren entre los distintos actores, medios de comunicación, partidos políticos y las instituciones públicas. Asimismo, la articulación implica colisiones o apoyos de otros actores, lo que a su vez obliga a estos a reinterpretar esos apoyos o amenazas en términos simbólicos e ideológicos (es decir en marcos cognitivos) (Alpízar, 2013.pp. 37-39). Para ello, resulta relevante a la hora de realizar investigaciones sobre el tema, identificar la forma cómo las personas proceden o llegan a ponerse de acuerdo para actuar colectivamente. Precisamente, en el desarrollo de ese aspecto, dan cuenta de las características organizativas y las estrategias desplegadas para el desarrollo de la movilización social (Alzate, 2008, p. 280).

En la Figura 5 se muestra de manera general las estrategias utilizadas por el primer bloque conformado por miembros de la comunidad de Tacares. Dentro de las estrategias utilizadas por la comunidad, se identificó el uso de acciones legales como la implementación de recursos de amparo contra instituciones del Estado. 
Uno de ellos fue la denuncia contra el AyA, SETENA y la Municipalidad de Atenas ante el Tribunal Ambiental, pues alegaban que hicieron un fraccionamiento de la viabilidad ambiental y por falsedades que se indicaron el formulario D2 (Bolaños, 2013, p. 8). Del mismo modo, se interpuso un recurso de amparo contra la SETENA, el AyA y el MINAE (expediente 13-007790), dicho recurso se dio con lugar y se declaró nula la viabilidad ambiental otorgada por SETENA al AyA para la utilización del agua.

Otra estrategia que se identificó fue la oposición a que la empresa MECO continuara con las obras en Calle Flores y Cataluña (Bolaños, 2013, p. 4). Por esto, se realizaron manifestaciones para impedir que las obras del proyecto continuaran y se tomó el lugar donde se almacenaba la tubería, acciones que la comunidad explicaba que se apegaban al régimen democrático y al derecho a la libertad de expresión. Del mismo modo, se recurrió a reuniones con diversos actores y se procedió a la realización de asambleas comunales, en las cuales se decidió formar una Comisión Técnica Negociadora $(\mathrm{CTN})^{8}$ que se reuniría y negociaría con el AyA para buscar una solución conjunta.

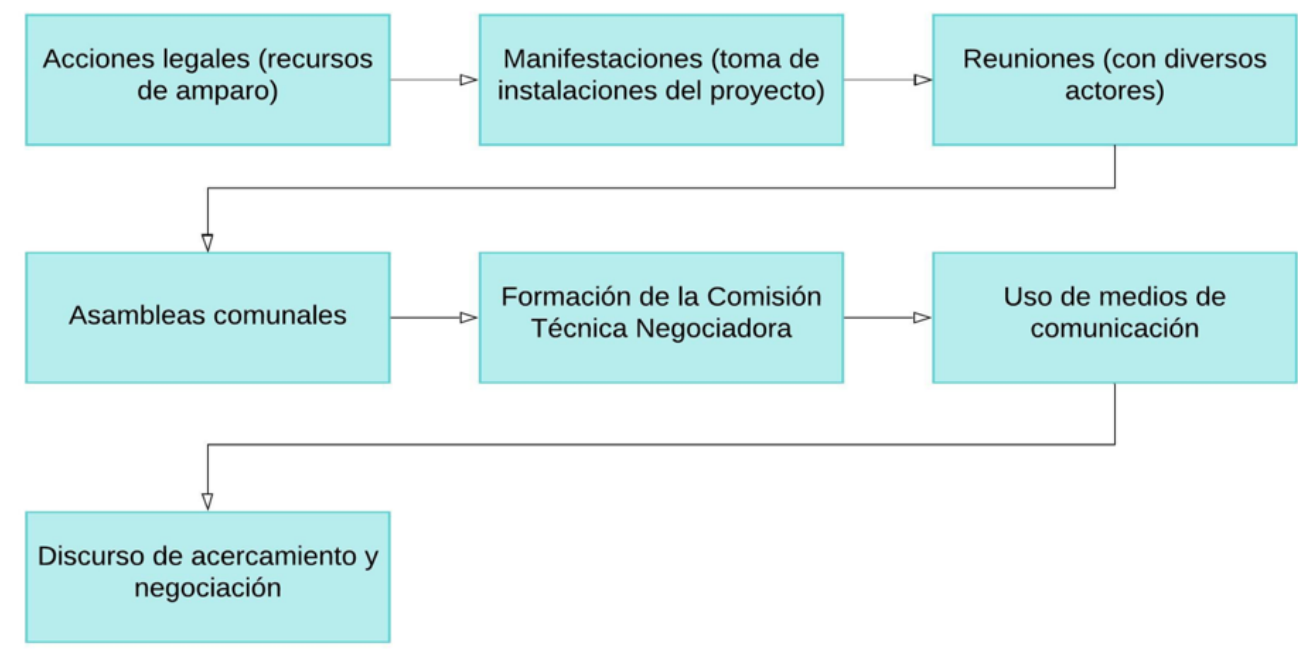

Figura 5. Estrategias de organización del primer grupo de la comunidad de Tacares. Fuente: Elaboración propia.

El segundo bloque mostró una oposición absoluta al proyecto y continuaron mostrando malestar por los daños causados por los trabajos de construcción sobre todo en infraestructura. Ligado a esta férrea oposición al proyecto, la estrategia de este sector de la comunidad fue no negociar con el AyA, así en un principio se rechazó las peticiones de la institución para retomar el diálogo, sin embargo, posteriormente se aceptó una mesa de diálogo en la cual medió la Defensoría de los Habitantes. Del mismo modo, como se puede observar en la Figura 6, se recurrió a acciones legales como el recurso de amparo interpuesto para detener la tala de árboles dentro del parque. Asimismo, hicieron uso de manifestaciones confrontativas. 
Las estrategias utilizadas por el segundo bloque se enfocaban más en mantener una oposición absoluta al diálogo, que fue construida a partir de la percepción de que el recurso hídrico le pertenece a la comunidad y que si este era tomado del parque podría atentar contra el abastecimiento futuro de Tacares sin contar con criterios técnicos que avalaran esta posición, manteniendo así una posición de resistencia y siendo, en ocasiones, confrontativa y reaccionaria.

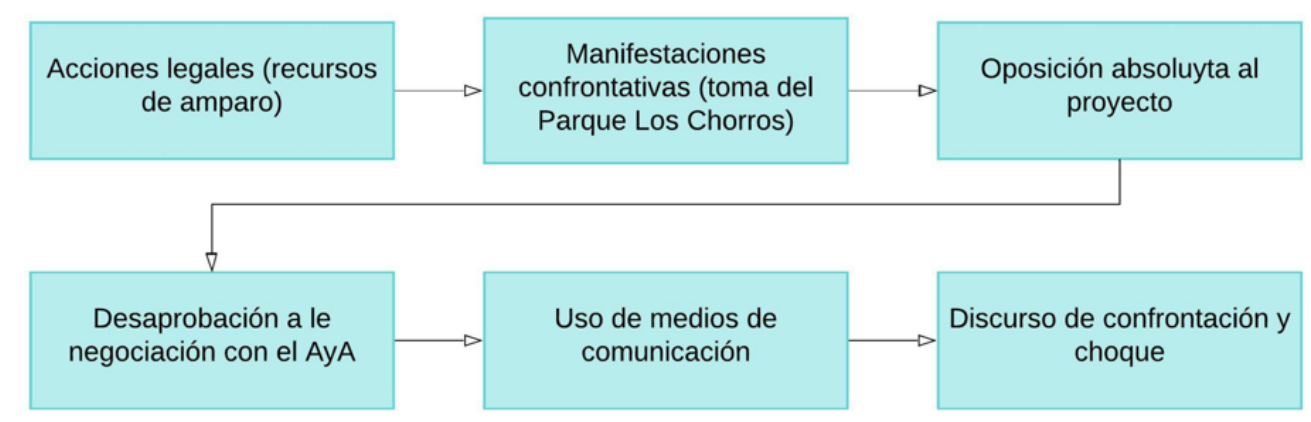

Figura 6. Estrategias de organización del segundo bloque de la comunidad. Fuente: Elaboración propia.

\section{EL PROCESAMIENTO INSTITUCIONAL DE LAS DEMANDAS POLÍTICAS DE LA COMUNIDAD DE TACARES}

Las demandas políticas de la comunidad de Tacares que fueron articuladas en las instituciones a través de estrategias y repertorios de acción muy diversos obligaron al Estado costarricense a buscar formas de responder a estas petitorias para poder continuar con el proyecto que se estaba desarrollando y que era considerado de suma urgencia culminar. Estas respuestas institucionales a las demandas son decisiones tomadas en la esfera pública sobre asuntos que en su mayoría competen a la colectividad, pero que no están aisladas de la incertidumbre sobre los resultados que pueda tener esa intervención o política pública. Más recientemente una de las características distintivas de las políticas públicas es el aumento de la conflictividad entre grupos sociales, actores políticos, entre ciudadanos y autoridades políticas (Dente \& Subirats, 2014, p. 48). Tal y como sucedió precisamente en este caso, donde una intervención del Estado en respuesta a una demanda generó un conflicto que se mantuvo durante siete años y retrasó la posibilidad de atender la necesidad que había sido planteada inicialmente.

Tras las demandas políticas articuladas por los distintos miembros de la comunidad, se generan una serie de respuestas dadas por las autoridades institucionales tras el procesamiento de estas peticiones planteadas. Es importante mencionar que el tratamiento a estas demandas defendidas por los diferentes miembros de la comunidad de Tacares a su vez variaron según el contexto político-institucional, 
en el tanto el cambio en dirigencias institucionales llevó a que se utilizaran diferentes estrategias para el abordaje de este conflicto. De esta forma, se abordarán a continuación las respuestas del Estado a las demandas políticas formuladas por los actores según las categorías utilizadas para la clasificación de éstas en el apartado anterior. Esto implica, por ende, el análisis general de las respuestas a las demandas procedimentales y garantistas, las conservacionistas y aquellas que articulaban un replanteamiento del proyecto que originó el conflicto en estudio como fueron más detalladas en el apartado anterior.

En primer lugar, respecto a las demandas procedimentales y garantistas que buscaban un mayor acceso a información y participación, la respuesta institucional a estas fue propiciar la creación de la Comisión Técnica Negociadora a través de la cual se buscaba dar a los miembros de la comunidad de Tacares una mayor participación y servir de canal para informar a la comunidad sobre el proyecto. A través de las reuniones realizadas con esta comisión, el AyA pretendía generar un espacio de análisis de datos e información y de verificación conjunta del proyecto (Astorga, comunicación personal, 5 de setiembre de 2019). Asimismo, además de las reuniones de negociación realizadas con la CTN, el AyA, a través de su presidencia ejecutiva, llevó a cabo reuniones informativas con el propósito de explicar a miembros de la comunidad y asadas vecinas sobre el proyecto y sobre lo acontecido con los actores organizados de Tacares. De acuerdo con Yamileth Astorga, el objetivo de estas actividades era "informar a la comunidad y aclararle dudas que tenían" (Astorga, comunicación personal, 5 de setiembre de 2019); sin embargo, ellos aseguran que en varias ocasiones sus intenciones se vieron truncadas por miembros de la comunidad que les bloqueaban esa posibilidad (Salazar, comunicación personal, 5 de setiembre de 2019).

Otra de las respuestas dadas a estas demandas por información fue la distribución de material escrito a la población tacareña con el propósito de ampliar su conocimiento sobre el proyecto, que aseguran se dio durante las sesiones informativas que sí pudieron ser llevadas a cabo. Asimismo, mencionan que con este mismo objetivo se hicieron esfuerzos por publicar en medios de comunicación local, incluso de forma pagada, que permitieran a las personas de Tacares estar al tanto de lo que sucedía (Salazar, comunicación personal, 5 de setiembre de 2019).

En segundo lugar, en lo que respecta a las demandas conservacionistas que buscaban la protección de los recursos y el abastecimiento futuro, los actores institucionales (específicamente aquellos del AyA) respondieron con la compra de trece hectáreas aledañas al lugar para la conservación de la fuente de agua del Parque Los Chorros así como con la instalación de un macro medidor que le permitiera a la comunidad verificar la cantidad de agua que estaría siendo extraída para ser llevada a Atenas (Astorga, comunicación personal, 5 de setiembre de 2019). Por otro lado, el AyA propuso para responder a esto continuar con los estudios hidrogeológicos de apoyo tanto a la fuente uno como a la dos que se encuentran en el Parque Los Chorros, así como con estudios de calidad de agua y la construcción de una obra calibradora que permitiera a cada una de las partes conocer la cantidad de agua consumida en el abastecimiento de sus comunidades (Junta Directiva del AyA, AT-2014-039, 2014). Finalmente, para las demandas 
políticas construidas en torno al replanteamiento del proyecto de Mejoras al Sistema de Abastecimiento de Atenas, la principal respuesta fue la apertura de un proceso de negociación con la comunidad a través de la CTN para el análisis de la propuesta original del proyecto y de las alternativas planteadas por los miembros actores comunales de Tacares. Se abrió por tanto un espacio de diálogo o discusión que además es un principio clave de los regímenes representativos (Manin, 2006, p. 7)

Es preciso mencionar que este proceso de negociación tuvo la participación constante del grupo de vecinos que desde el inicio conformaron la CTN (es decir, el primer grupo de vecinos). Sin embargo, la contraparte institucional tuvo algunos cambios propios del escenario político nacional que llevaron a modificar su conformación y a la introducción de nuevos actores, especialmente la nueva presidencia ejecutiva y su equipo de trabajo. Por lo que es posible comprender este espacio en dos momentos distintos separados a partir de febrero del año 2014. Para este caso se tomó en cuenta el criterio técnico institucional y los criterios políticos y técnicos articulados por los vecinos de Tacares que se habían organizado en el primer grupo, pero el acuerdo alcanzado fue desaprobado por la comunidad, principalmente por el segundo grupo de vecinos mencionado anteriormente y concluyó con el desarrollo del proyecto casi tal cual estaba planteado en un inicio.

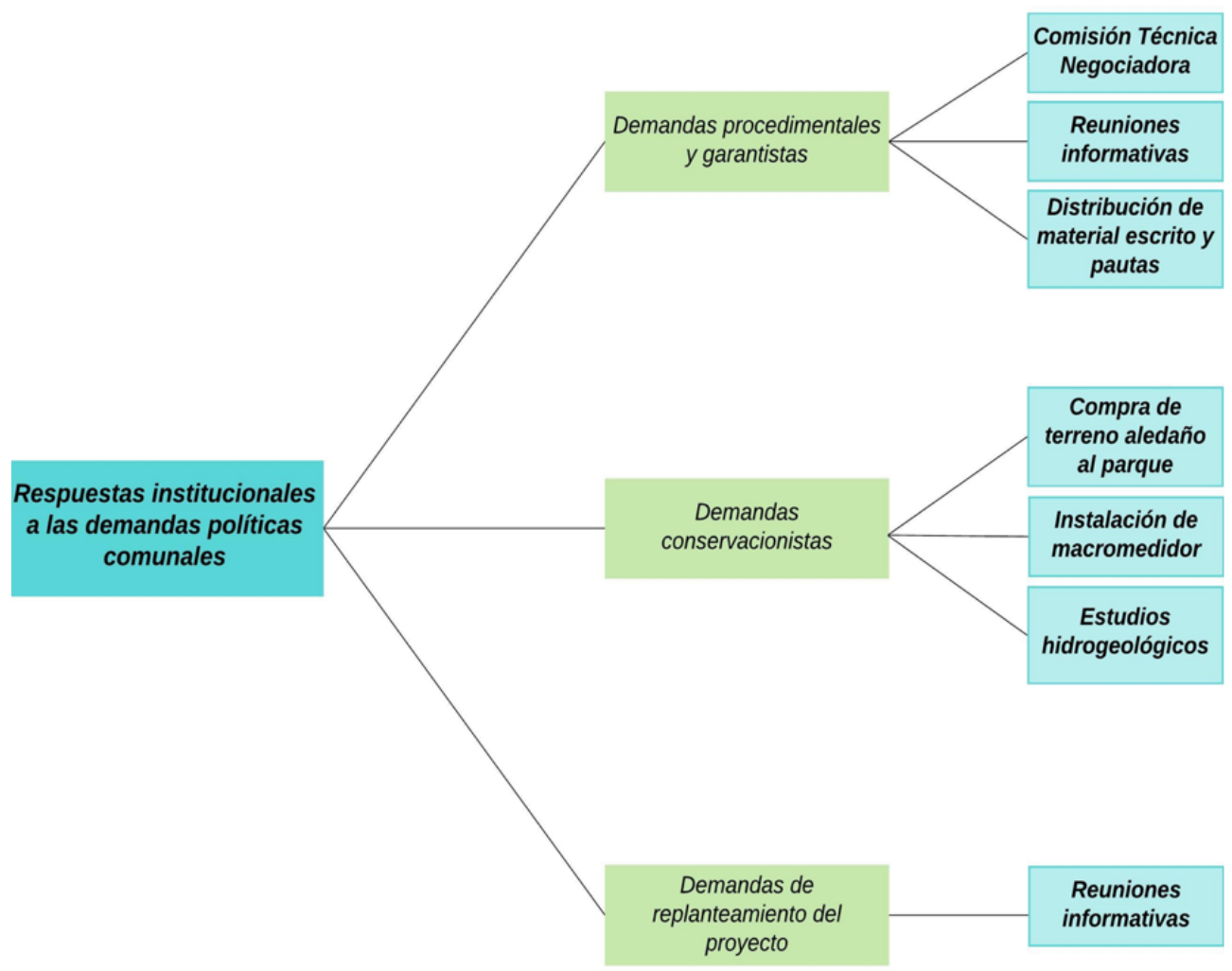




\section{REFLEXIONES FINALES}

A partir del análisis de marcos abordado en los apartados anteriores es posible determinar cómo las principales demandas políticas de la comunidad estaban asociadas a la representación política que, como se mencionó anteriormente, implica que el pueblo esté presente en la acción gubernamental (Pitkin, 1985, p. 247). Este aspecto no fue percibido de esta forma por este grupo de vecinos que se sentía no solo excluido del proceso de formulación de este proyecto, sino también que consideraban que el accionar institucional no iba acorde al interés que ellos tenían como gobernados. Es decir, estos actores cuestionaban a través de sus demandas la existencia de una verdadera representación como actuación sustantiva, y con ello de cierta forma cuestionaban las prácticas paternalistas, verticales y excluyentes con las que Castro (2012) caracteriza la gestión y gobernabilidad del agua en América Latina.

Cada uno de los marcos empleados por los vecinos de Tacares construyen demandas que, de acuerdo con la clasificación de causas de conflictividad por recurso hídrico de Castro, Kloster y Torregrosa (2004), obedecen a aspectos sociopolíticos que tienen que ver con la gobernabilidad del recurso y los servicios. Esto en el tanto las reclamaciones a la institucionalidad iban vinculadas a la forma en que el Estado mismo gestiona el recurso para satisfacer las demandas de este, o lo que los autores definen como causas de conflictividad por condiciones básicas de acceso y estándares de servicio (pp. 346-347). A su vez, articulan lo que previamente se definió como una contienda política, pues expone la presencia de un conflicto de intereses entre distintos actores, en este caso los vecinos de Tacares y el Estado representado por el AyA.

Las demandas construidas por los miembros de la comunidad e identificadas a través de los marcos apelan a formas de control social, en lo que Castro (2012) plantea como la búsqueda de subordinación de las instituciones públicas al control social ejercido por los ciudadanos, expresado en diferentes formas, pero fundamentalmente en la búsqueda de lo que se denomina el ejercicio sustantivo de la ciudadanía. Esto a su vez es el resultado de un movimiento latinoamericano que desde la década de los ochenta viene cuestionando el control público sobre el recurso y de una creciente amenaza de que los principios mercantiles pasen a tener un rol dominante en el funcionamiento del Estado (p. 12).

Se trata, para este caso, a grandes rasgos de demandas por la capacidad de ejercer una ciudadanía activa que pueda conocer más a profundidad el manejo que se le da al recurso, pero también que incidir sobre este de forma participativa y a través de un escrutinio que Castro (2012) comprende como "control ciudadano" (p. 11). A partireste, sin embargo, se canalizaron demandas con intereses sumamente variados y distintos entre sí; unas apelando a la necesidad de información, pero entendiendo el agua como un recurso para las necesidades colectivas y otras por el contrario en la búsqueda de su acaparamiento.

Es posible entonces identificar las estrategias de los vecinos de la comunidad como acciones colectivas en tanto se enmarcaron en un programa y un interés compartido a lo interno de ambos grupos mencionados. Estas, a su vez, estuvieron ligadas a un escenario de contienda política definido a partir de Tilly y Tarrow, 
donde se reunieron aspectos como la contención, la acción colectiva y la política en una búsqueda por incidir en la estructura y sobre todo en una agenda institucional que se resumía principalmente en el interés por desarrollar este proyecto en el Parque Los Chorros. Asimismo, en algunos de los casos es posible identificar estrategias de participación política que se consideran no tradicionales, con las cuales precisamente los actores comunales buscaron desplazar en algunos casos los canales tradicionales que se dan desde la esfera institucional como resultado de una percepción de injusticia.

Las respuestas institucionales, por su parte, se inclinaron hacia el facilitamiento de espacios de diálogo, con el fin de propiciar una mayor participación y generar un canal para informar a la comunidad sobre el proyecto. Sin embargo, estos buscaron implementarse hasta que ya había conflictividad y descontento, lo que de alguna forma pudo haber condicionado la capacidad para llegar a un acuerdo. Asimismo, la formación de identidades políticas bajo esta dicotomía de un nosotros y un ellos puede rechazar que haya un espacio donde se pretendan soluciones racionales, pues muchas veces para salir de un conflicto los procesos de negociación pueden ocasionar retrasos, lo que cuestionar hasta qué punto estos procesos de negociación son factibles cuando hay identidades políticas marcadas e intereses en conflicto que no encuentran un punto de convergencia.

Es posible entonces identificar desigualdades y asimetrías de poder entre la institucionalidad y las comunidades como resultado de un Estado que es percibido como desinvolucrado en el tanto no fomenta la participación de las comunidades e insiste en desarrollar políticas públicas top down para la gestión del agua. Además, estas siguen siendo justificadas a través de la despolitización de estos procesos mediante discursos meramente técnicos que descartan la posibilidad de entenderlos dentro de un ciclo hidro social según el cual la circulación del agua es un proceso físico, pero también social (Swyngedouw, 2019, p. 49).

Ahora bien, es importante mencionar la posible existencia de desigualdades entre los mismos actores de la comunidad, quienes también en algunos casos responden a intereses privados y ceden a la presión de actores que no siempre son evidentes y visibles dentro del conflicto, pero que podrían articular a las comunidades en función de sus intereses personales. Así, para el caso es posible mencionar la posible movilización de intereses empresariales y económicos en la obstrucción al proyecto de Mejoras al Sistema de Abastecimiento de Atenas en función de canalizar el agua hacia inversiones que se llevarían a cabo en el cantón de Grecia (comunicación personal con informante clave 4, 30 de julio del 2019).

Esto, por ende, demuestra la urgencia planteada por Swyngedouw (2019) de analizar cómo los derechos públicos al agua se pueden transformar social, económica y políticamente en derechos de propiedad exclusivos, cuyo manejo se da a través de mecanismos de mercado que generan acumulación mediante el despojo y la inclusión sistemática de partes del ciclo hidro social en tácticas de acumulación de los actores privados. Esto refleja una vez más la idea de que el acceso al agua está organizado a través del poder del dinero, independientemente de las necesidades sociales, humanas o ecológicas (Swyngedouw, 2019, pp. 52). 


\section{NOTAS}

1 Es importante mencionar que, si bien se desarrolló un enfrentamiento entre comunidades vecinas, el conflicto principal fue entre los vecinos de Tacares y el Estado a través del AyA. Es por esto que el presente artículo se centra en el análisis de la interacción entre estos actores durante el período de conflictividad.

2 Se trata de asociaciones administradoras de los Sistemas de Acueductos y Alcantarillados comunales en Costa Rica, las cuales administran bajo un esquema de delegación de la administración acordado con el AyA.

3 El término de la representación también aplica para instituciones debido a su estructura general y al propósito original que tienen y que se suponen que encarnan, al margen de que en un caso concreto originen o no la sustancia de la representación. Es así, que Pitkin (1985) describe a las instituciones como ejecutoras prácticas de la representación, pues sin la institucionalización, la representación no pasaría de ser un concepto vacío (pp. 264-265). Es decir, todas las instituciones que conforman el Estado son la estructura que posibilita las relaciones de representación entre el ciudadano y el político.

Se entiende, por ende, un actor como aquellos que simplemente actúan, no quienes tienen interés en actuar o los que deberían hacerlo; solo esos cuyas acciones buscan incidir en la política pública, es decir, personas que actúan con el fin de obtener algún resultado, excluyendo a los que se ausentan en ese proceso (Dente \& Subirats, 2014, pp. 73-75).

$5 \quad$ Se entiende por conflictos socioambientales, partiendo de Svampa (2013), aquellos ligados al acceso y control de los bienes naturales y el territorio, que suponen, por parte de los actores enfrentados, intereses y valores divergentes en torno de ellos, en un contexto de gran asimetría de poder. Asimismo, estos "expresan diferentes concepciones sobre el territorio, la naturaleza y el ambiente, al tiempo que van estableciendo una disputa acerca de lo que se entiende por desarrollo y, de manera más general, por democracia". Esto último entendiéndolo en el tanto de que los proyectos extractivos reconfiguran el territorio en su globalidad y con ello no solo determinan las formas económicas y sociales existentes, sino que también el alcance mismo de la democracia, cuando esos proyectos se imponen sin el consenso de las poblaciones y generan fuertes divisiones en la sociedad (Svampa, 2013, p. 40).

6 De acuerdo con Goffman en Chihu (2012), este se interesa por examinar cómo se genera la experiencia y el conocimiento acerca del mundo; así, la posibilidad de que surja algún tipo de sentido de realidad en los actores se viabiliza por la existencia de principios de organización o marcos que permiten llegar a una definición de la situación. De modo que, los marcos de comprensión orientan no sólo la interpretación de las acciones sociales, sino también la realización misma de las actividades sociales. Para Goffman el marco (frame) es una palabra que se utiliza para referirse a los elementos básicos que se es capaz de identificar en situaciones sociales y que permiten generar esquemas interpretativos (en Chihu, 2012. p.81). 
$7 \quad \mathrm{Al}$ respecto, el geólogo Mario Arias llevó a cabo una serie de estudios técnicos pagados por la Asada de Tacares, los cuales determinaron que ambas nacientes descargan agua proveniente del mismo acuífero, Colima, y que el efecto del fallamiento que hay en el lugar permite que el agua subterránea ascienda a la superficie y pueda salir por ambos puntos de afloramiento. Sin embargo, las condiciones para la captación no son exactamente las mismas, ya que en una de las nacientes el agua aflora en roca masiva, que es precisamente donde está la captación actual donde es más factible por las condiciones propias de la roca que permiten crear una estructura ingenieril relativamente más fácil. Mientras que la otra, la fuente dos, la roca es más disgregada por lo que desde el punto de vista ingenieril generaba o podía generar un grado de complicación mayor para hacer una infraestructura de captación de agua.

8 La formación de la CTN buscaba, de acuerdo con los actores de la comunidad entrevistados, dar una batalla técnica al AyA, pues su objetivo era ser una oposición seria. Para ello se realizó una inversión económica para preparar a esta comisión con profesionales destacados en diversas ramas y poder así acopiar información técnica, científica y realizar estudios que les permitieran elaborar una propuesta en conjunto con AyA que posteriormente sería presentada a toda la comunidad.

\section{REFERENCIAS}

Alonso, S., Volkens, A. \& Gómez, B. (2012). Análisis de contenido de textos políticos. Un enfoque cuantitativo. Madrid: Cuadernos Metodológicos.

Alpízar, F. (2019). Conflictos por el agua en Costa Rica de 1980 a 2017. En Alpízar, F. (Ed.), Agua y Poder en Costa Rica 1980-2017 (pp. 17-51). San José, Costa Rica: Centro de Investigación y Estudios Políticos.

Alpízar, F. (2013). ¿Democracia ecológica? Las instituciones, la participación política y las contiendas por el agua en Costa Rica (1821-2010) (Tesis de doctorado) . España: Universidad Complutense de Madrid.

Alzate, M. (2008). Esbozo teórico de la acción política colectiva: experiencias colectivas alternativas frente a las relaciones hegemónicas de dominación. Investigación \& Desarrollo, 16, 278-303.

Ávila, P. (2008). Déficits legislativos y gestión dialogada de conflictos hídricos enAmérica Latina: la experiencia del Tribunal Latinoamericano del agua. En Gobierno de Aragón (Ed), El agua, derecho humano y raíz de conflictos (pp.129-140). Aragón: Serie Estudios para la Paz.

Barrantes, A. (10 de agosto de 2014). Atenas: un cantón donde se sobrevive con tres horas de agua al día. La Nación. Recuperado de http://www.nacion.com/nacional/politica/canton-sobrevivehoras-agua-dia_0_1432056828.html.

Bautista, J. (2016). Los conflictos por el agua y las enseñanzas de la causa Mendoza. En Urteaga,

P., Guevara, A., y Verona, A. (Eds.), El Estado frente a los conflictos por el agua (pp. 55-70). Lima: Pontificia Universidad Católica del Perú. 
Bazán, C. (2012). Conflictos por el agua en el Estado de Morelos (2000-2010). En Perevochtchikova (Coord), Cultura del agua en México: conceptualización y vulnerabilidad social (pp. 139-156). México: Serie Las Ciencias Sociales.

Bolaños, R. (Febrero 2013). Acueductos y Alcantarillados obligado a cambiar frentes de trabajo para Atenas. Mi Tierra.

Bottaro, L., Latta, A., \& Sola, M. (2014). La politización del agua en los conflictos por la megaminería: Discursos y resistencias en Chile y Argentina. Revista Europea De Estudios Latinoamericanos Y Del Caribe, 97, 97-115.

Caballero, H. (2008). El agua y los objetivos de desarrollo del milenio: ocho razones y una década para la acción. En Gobierno de Aragón (Ed), El agua, derecho humano y raíz de conflictos (pp. 3153). Aragón: Serie Estudios para la Paz.

Castro, E. (2008). Proposiciones para el examen teórico y empírico de la privatización: el caso de los servicios de agua y saneamiento en América Latina. En Gobierno de Aragón (Ed), El agua, derecho humano y raíz de conflictos (pp. 367-390). Aragón: Serie Estudios para la Paz.

Castro, E. (2012). Luchas sociales por el agua y el proceso de democratización en América Latina. En Perevochtchikova, M. (Coord.), Cultura del Agua en México: conceptualización y vulnerabilidad social (pp. 99-108). México: Serie Las Ciencias Sociales.

Castro, E. Kloster, K. \& Torregrosa, M. (2004). Ciudadanía y gobernabilidad en México: el caso de la conflictividad y la participación social en torno a la gestión del agua. En Jiménez y Marín (Eds). El agua en México vista desde la Academia (pp. 339-370). México: Academia mexicana de las Ciencias.

Chihu, A. (2012). La teoría del framing: un paradigma interdisciplinario. Acta Sociológica, 59, 77-101.

Collado, J. (2012). Gestión integrada de los recursos hídricos y prestación de los servicios públicos de agua potable y saneamiento. En Perevochtchikova, M. (Coord), Cultura del agua en México: conceptualización y vulnerabilidad social (pp. 231-256). México: Serie Las Ciencias Sociales.

Contreras, C., Correa, F. \& García, L. (2005). Participación política no convencional: culturas de protesta vs. culturas institucionales. Polis, 1, 181-210.

Dente, B. \& Subirats, J. (2014). Decisiones públicas: análisis y estudio de los procesos de decisión en políticas públicas. Barcelona: Ariel.

Echeverría, J. (2017). Gobernanza del agua. Una necesidad sentida frente al agotamiento de los recursos hídricos. Caso Colombia. En Rodríguez-Mateo (Ed.), Centroamérica: agua, cultura y territorio (pp. 274-285). Heredia: Actas I Congreso Internacional.

Foronda, M. (2008). El agua como derecho humano. El caso de América Latina. En Gobierno de Aragón (Ed). El agua, derecho humano y raíz de conflictos (pp. 297-342). Aragón: Serie Estudios para la Paz.

Fornaguera, I. (2014). Lío por agua tiene a Grecia y Atenas enfrentados. La Nación. 
Galindo, J. (2012). Gobernanza, gobernabilidad y gestión del agua en México. En Perevochtchikova, M. (Coord), Cultura del agua en México: conceptualización y vulnerabilidad social (pp. 257278). México: Serie Las Ciencias Sociales.

García, P. (1999). Conflictos sociales por el agua en la región norte de México: Los casos de Tijuana, Durango y Monterrey. Ecología Política, (18), 37-44.

Hidalgo, J. (2012). Gobernabilidad y gestión del agua en México. En Perevochtchikova, M. (Coord), Cultura del agua en México: conceptualización y vulnerabilidad social (pp. 279-288). México: Serie Las Ciencias Sociales.

Junta Directiva del AyA. (2014). Acta No. 2014-03. Sesión extraordinaria. Instituto Costarricense de Acueductos y Alcantarillados.

Latta, A., \& Gómez, A. (2014). Agua y megaproyectos en Latinoamérica: Una introducción. Revista Europea De Estudios Latinoamericanos Y Del Caribe, 97, 51-54.

Manin, B. (2006). Los principios del gobierno representativo. Madrid: Alianza Editorial.

Mar, M. (2012). Cultura del agua en México concepto, marco programático gubernamental (20072012) y actores, líneas principales de acción de Conagua, importancia de la planeación y la evaluación. En Perevochtchikova, M. (Coord), Cultura del agua en México: conceptualización y vulnerabilidad social (pp. 83-98). México: Serie Las Ciencias Sociales.

Mouffe, C. (2000). La paradoja democrática: El peligro del consenso en la política contemporánea. Barcelona: Editorial Gedisa.

Mouffe, C. (2007). En torno a lo político. Buenos Aires: Fondo de Cultura Económica.

Mora, J. (2017). Gobernanza del agua en Distritos de Riego de Costa Rica: El Distrito de Riego ArenalTempisque (DRAT). En Rodríguez-Mateo (Ed.), Centroamérica: agua, cultura y territorio (pp. 298-315). Heredia, Actas I Congreso Internacional.

Murillo, A. (2014). Las peleas comunales por el agua proliferan en Costa Rica. El País. Recuperado de https://elpais.com/internacional/2014/10/14/actualidad/1413302409_043950.html

Ojeda, D. (2016). Los paisajes del despojo: propuestas para un análisis desde las reconfiguraciones socioespaciales. Revista Colombiana de Antropología, 52, 19-43.

Pare, L. (2012). Una nueva cultura del agua: la cogestión de cuenca. En Perevochtchikova, M. (Coord), Cultura del agua en México: conceptualización y vulnerabilidad social (pp. 177-192). México: Serie Las Ciencias Sociales.

Peña, J. (2008). Algunas dificultades históricas y cotidianas para resolver los conflictos por el agua en la cuenca de México. En Peña, J. (Ed.), El agua, espejo de los pueblos (pp. 83-106). México: Plaza y Valdes.

Pérez, M. B., Santamaría, J. S., \& Piña, C. M. (2006). Los conflictos por agua en México. Diagnóstico y análisis. Gestión y Política Pública, 15, 111-143. 
Petrescu, D., Petrescu-Mag, I. \& Gavriletea, D. (2011). Integrative negotiation for sustainable water management. Air Water Compon Environ, 1, 14-21.

Pitkin, H. (1985). El concepto de la representación. Madrid: Centro de Estudios Constitucionales.

Sala Constitucional. (2011). Recurso expediente 07-008098-0007-CO.

Sánchez-García, J. (2015). La administración municipal del agua en los Valles Centrales de Oaxaca durante el Porfiriato. En Contreras, Navarro y Rosas (Coords.), Agua, Estado y sociedad en América Latina y España (pp. 235-258). Sevilla, Escuela de Estudios Hispanoamericanos.

Segrelles, J. (2007). Geopolítica del agua en América Latina: dependencia, exclusión y privatización. Simposio Polaco-Mexicano. Polonia: Universidad de Varsovia.

Secretaría Técnica Nacional Ambiental (SETENA). (2014). Resolución No1614-2014-SETENA.

Svampa, M. (2013). «Consenso de los Commodities» y lenguajes de valoración en América Latina. Nueva Sociedad, 244, 30-46.

Swyngedouw, E. (2019). La economía política y la ecología política del ciclo hidro-social. En Castro, E. (Ed.), Territorialidades del agua: conocimiento y acción para construir el futuro que queremos (pp. 48-54). Ciudad Autónoma de Buenos Aires, Argentina: Waterlat-Gobacit.

Vallejo, S. (2011). La gestión del agua como bien público. Quito: Flacso Ecuador.

Viñuales, V. (2008). Buenas prácticas sociales sobre la sostenibilidad y la extensión de los servicios de agua. En Gobierno de Aragón (Ed), El agua, derecho humano y raíz de conflictos (pp. 391-406). Aragón: Serie Estudios para la Paz. 